\title{
CRECHE: Um espaço narrativo
}

\author{
Day care A narrativespace
}

\section{Jacqueline Müllich Fensterseifer}

Psicóloga e aluna do Curso Transtornos do Vínculo e Clínica da Perinatalidade - Diploma Universitário - uma parceria entre o Instituto Leo Kanner, Porto Alegre- Brasil; a Universidade de Montevidéu -Montevidéu - Uruguai; ea Universidade deAixenProvence - Provence - França. Santa Cruz do Sul, RS - Brasil, e-mail:jacquelinemullichf@ gmail.com

\section{Resumo}

Através de olhares, gestos e palavras, logramos saber um pouco mais acerca da subjetividade do ser humano, e, em se tratando de bebês, podemo-nos valer da observação destes, possibilitando, assim, um maior conhecimento sobre eles. Cientes de que, no comportamento observável do bebê temos acesso à sua subjetividade, este artigo, fruto de repetidas observações, esboça, através de uma articulação teórica entre as observações realizadas e autores consultados, algumas hipóteses sobre o funcionamento mental do ser estudado. As escolas de educação infantil, ou como são conhecidas popularmente, as creches, são construções contemporâneas advindas do desenvolvimento e crescimento industrial, o que alavancou a necessidade de uma mudança na forma de se pensarem as crianças; e, para que fossem compreendidas, também se fez necessária uma maior atenção à etapa do desenvolvimento chamada infância. Existe hoje uma consciência clara de que a creche desempenha várias funções, entre elas, a de representar um local onde a educação e a estimulação de conhecimentos se fazem presentes. Em cuidados físicos, psíquicos, e a socialização básica à clientela que a frequenta, bem como através da narratividade das cuidadoras, poderá a creche ser encarada como uma base segura, que proporcionará um apego seguro e, consequentemente, um desenvolvimento físico e psíquico mais saudável.

Palavras-chave: O bservação de bebês; Creche; Narratividade. 


\begin{abstract}
Through watching, gestures and words we can get to know a little bit more about human being's subjectivity, and when talking about babies we can use observation, so getting the greatest possible knowledge about them. Being aware that, in a baby's observable behavior we have access to his subjectivity, this article, a result of repetitive observations, through a theoretical articulation between observations made and consulted authors, outlines some hypotheses about mental operation of the being studied. Infantile education schools, or day cares as popularly known, are contemporaneous constructions coming from industrial growth development, what has leveraged the need for children changing their way of thinking; and, for them to be understood, a greater attention to the development stage called childhood was also necessary. Today there is a clear conscience that day cares perform various duties, among them representing a place where education and knowledge stimulation are present. Together with physical, physic care, and basic socialization of the regular clientele that frequents them, as well as through the caretakers' narrativity, day cares can be faced as a safe base that will provide a safe affection and, consequently, a healthier physical and physic development.
\end{abstract}

Keywords: Baby observations; Day care; Narrativity.

"Nada sabemos da alma senão da nossa; as dos outros são olhares, são gestos, são palavras, [...]"

Fernando Pessoa

\section{INTRODUÇÃO}

As palavras poéticas de Fernando Pessoa nos sugerem que, através de olhares, gestos e palavras, podemos saber um pouco mais da subjetividade do ser humano. Em se tratando de bebês, devemo-nos valer da observação destes, pois "não conseguem expressar seus estados internos por meio de verbalização ou de jogos simbólicos" (Brazelton \& Cramer, 1992). Para que conheçamos um pouco mais sobre eles, necessitaremos fazê-lo através do comportamento observável, durante uma sessão de observação; assim, teremos acesso à "manifestação de sua experiência subjetiva" (Brazelton \& Cramer, 1992).

Dessa forma, o presente artigo analisa alguns comportamentos observados, sob a égide das teorias e autores estudados no Curso Transtornos de Vínculo e Clínica da Perinatalidade(DiplomaUniversitário). Essecurso realizou-se através de uma parceria entre o Instituto
Leo Kanner - Porto Alegre - Brasil, a Universidade de Montevidéu - Montevidéu - Uruguai, e a Universidade de Aix-en-Provence - Provence França, nos anos de 2005, 2006 e 2007.

As observações aqui referidas ocorreram em uma Escola Municipal de Educação Infantil (popularmente denominada de creche), em um município do interior do Rio G rande do Sul - Brasil. Mantida pela prefeitura do município, possui acompanhamento de nutricionista, pedagoga, psicóloga e orientadora educacional. As crianças que a frequentam são filhas e filhos de mães que trabalham em empresas públicas ou privadas deste município durante 0 dia; aliás, essa é a condição para que as crianças possam frequentar a creche. A organização das turmas se dá por idade em várias salas, com duas ou três monitoras/ atendentes, sendo que o número de ocupantes varia de 12 a 15 . Foram realizadas três observações de uma hora-relógio cada, nas dependências da Escola Municipal de Educação Infantil (creche). 0 bebê observado tinha 
no dia da primeira observação, seis meses e 28 dias de idade; já por ocasião da segunda observação, um ano, dois meses e 28 dias; e por fim, na terceira observação, um ano, quatro meses e quatro dias.

Existe hoje uma consciência clara de que a creche desempenha várias funções, entre elas a de ser um lugar onde a educação e a estimulação de conhecimentos se fazem presentes. Junto com os cuidados e socialização, básicos à clientela que a frequenta, é também um espaço para 0 desenvolvimento da autonomia do bebê.

Tem-se ciência, por outro lado, de que, por muito tempo, a educação da criança foi considerada como umaresponsabilidade da família; assim, era juntamente com os adultos que a cercavam e as crianças que a precediam, que ela aprendia a se tornar membro desse grupo, a participar das tradições importantes, e a dominar os conhecimentos necessários a sua so brevivência.

Para que tivéssemos escolas de educação infantil e creches como hoje, houve a necessidade de mudança na forma de se pensarem as crianças; e, para que se as compreendessem também se fez necessária maior atencão à etapa do desenvolvimento, chamada infância. "O surgimento dasinstituições deeducação infantil esteve de certa forma relacionado ao nascimento da escola e do pensamento pedagógico moderno, que pode ser localizado entre os séculos XVI e XVII" (Bujes, 2001).

A educação infantil que conhecemos hoje é uma construção recente, em constante movimento e aperfeiçoamento. As creches e as pré-escolas surgiram após a invenção da escola, e o surgimento daquelas está intimamente relacionado com o trabalho materno fora do lar, que teve seu início quando da Revolução Industrial. Juntamente a esse movimento, devemos ter presente que surgia uma nova estrutura familiar, conjugal e social. As várias modificações econômicas e sociais havidas provocaram um afastamento da díade mãe-bebê. E, desde que a primeira creche foi criada, em Paris (1844), inicialmente com o intuito de "abrigar crianças recolhidas nas ruas e filhas de operárias" (Rizzo, 1984), o movimento de criação de creches não cessou, e hoje, cada vez mais, se apresenta como uma necessidade urbana.

\section{A importância da narratividade desde a 1 a infância}

A o nos remetermos ao léxico, verificamos que narração é "a exposição escrita ou oral de um fato," (Dicionário Aurélio - Século XXI). Essa exposição/fala é de suma importância para 0 crescimento saudável dos bebês, mesmo porque, muitas vezes, significa as experiências que esse bebê vive. Assim, de acordo com V. Guerra (comunicação Verbal, 18 de novembro de 2005), "a narrativa permitirá e concederá uma relação de continuidade; por consequência, a narratividade sempre tem a função de ligação," devolvendo, desse modo, "a sensação de continuidade na vida" (Stern, 2007). N essa linha, retomamos um excerto da primeira observação realizada, para demonstrar que, nesse momento, o bebê observado não encontra eco em suas ações: "[...] ele veste um tiptop azul, da cor azul-céu, bem suave, e um babeiro atoalhado de bichinhos. Estava só, acompanhava com os olhos os movimentos ao seu redor. Suas mãos estavam sobre a 'tampa da cadeira', sem nenhum brinquedo [...];" "[...] a monitora deixa sobre a tampa da cadeira um outro brinquedo de borracha para o bebê e diz: 'ó o banana de pijamas'. 0 bebê pega o mesmo e logo o põe na boca, o tira, 0 brinquedo faz um quic, ele nem se assusta, parece que já está habituado ao som do mesmo. Olho para o bebê, que balança seu corpo ao som da música, vejo que o banana de pijamas está no chão e que o bebê está sem nada nas mãos, olhando para o chão onde está o banana de pijamas [...]." As monitoras nesse momento são extremamente econômicas na sua comunicação verbal, o que gera uma falta de atribuição de sentido e significado nas ações do bebê observado.

No segundo momento de observação, 0 mesmo bebê encontra-se em outra sala, com outras monitoras/ atendentes. Agora, percebemos queexiste uma tentativa de realizar uma breve conversa, pois, em determinado momento, a monitora demonstra uma atenção conjunta, começando a desenvolver uma narrativa quando da troca da fralda: "[...] A monitora seaproximou do bebêobservado e o pegou, dizendo: 'vamos ver se tem xixi?' Colocou-o sobre 0 trocador e conversou com ele. Vimos que o bebê olhava para 0 alto e ria, ela apontava para cima e também ria com ele, aproximando-se de seu pescoço, como que se fosse beijá-lo, fazendo carinho - parecia que interagiam de forma amistosa [...]."

Na terceira observação, o bebê observado continuava na mesma sala, com as mesmas monitoras. Confirmamos uma escassa narratividade de uma delas, desta vez quando da hora do lanche: "[...] Enquanto comia, ela repetia: 'Mhmmm, mas que creme bom! Ai ai ai, já engoliu tudo??? Vamo 
comê mais um pouquinho?'” No excerto acima, percebe-se que a monitora dá significado ao creme que as crianças ingerem, mas poderia falar/ conversar muito mais, atribuindo maior valor à ação de se alimentar. A narratividade, por ser uma unidade lúdica, tem a ver com a atribuição de sentidos; sentidos estes que nos remetem à produção de afetos; afeto este que, mais tarde, poderá ser associado aos transtornos alimentares, ou ainda, como designa Winnicott, aos "distúrbios do apetite" (Winnicott, 2000), hoje uma constante na prática clínica.

Bernard Golse (2003) refere que a narratividade é o produto de interações precoces e, por sua vez, ordena os processos de ligação. Esse ordenamento permite ao bebê partilhar seus conflitos, suas dificuldades, enfim, suas experiências; e, em momentos oportunos, resignificá-los através da repetição oral de suas experiências traumáticas. Para tanto, necessário se faz um cuidador que esteja atento a esse bebê, pois aquele, através da fala (narratividade), irá conferir sentido às experiências vivenciadas por este, experiências estas, muitas vezes, materializadas através do brincar.

\section{Aprender a brincar: Observando a (im)possibilidade}

"O brincar na infância é um fenômeno universal, queépróprio do estado de saúde" (G addini, 1982); brincar este que certamente facilitará 0 processo de maturidade do bebê e lhe proporcionará saúde, além de introduzi-lo na relação com seus cuidadores, através de uma comunicação própria. Ao brincar, o bebê vive um momento de controle sobre o objeto que possui nas mãos e, se formos pensar em processos intrapsíquicos, origina sentimentos de onipotência, colaborando com o desenvolvimento saudável do bebê. Assim sendo, "o brincar é uma experiência, é sempre uma experiência criativa, é uma experiênciaque se desenvolve em uma dimensão de espaço-tempo, enfim, é uma forma fundamental de vida" (G addini, 1982).

Uma experiência completa é aquela em que, num primeiro momento, há a percepção do objeto, passando-se à exploração deste, a uma excitação e dúvida, provocando sua queda (separação). Para que essa vivência seja completa, de acordo com S. Célia (comunicação pessoal, dia 17 de setembro de 2005), "a mãe ou a cuidadora devem retornar ao bebê o brinquedo/objeto caído, concedendo-lhe a possibilidade de completar a simbolização do objeto retido por alguns instantes em suas mãos para reiniciar suas explorações sobre 0 mesmo". Evidencia-se, desse modo, que o processo de simbolização é sinônimo de subjetividade, proporcionando condiçõesparaqueo bebêdesenvolva bem a linguagem. Dessa forma, percebe-se que a palavra é uma garantia para o início da transformação da equação simbólica, e que a linguagem, por sua vez, é um grande organizador do psiquismo.

Assim sendo, é possível distinguir três estágios principais no relacionamento de uma criança com um objeto: "Primeiro estágio:reflexo depreensão precoce; reclusão; tensão, incluindo preensão voluntária emergente e, a lenta passagem do objeto à boca. Segundo estágio: abocanhar o objeto; uso casual do objeto em exploração experimental. Terceiro estágio: afastamento" (Winnicott, 1983).

Muitas vezes, devido à imaturidade motora do bebê, no segundo estágio, o objeto cai de suas mãos e, algumas vezes, este é recolhido e devolvido ou não ao bebê, para que ele finalize sua descoberta da coisa. Pensando-se no bebê observado, isso é preocupante, pois, quando eleestádepossedeum objeto/ brinquedo, não consegue completar sua experiência de simbolização, eis que nenhuma cuidadora devolve a ele os objetos/ brinquedos que porventura tinha nas mãos, negando-lhe a motivação para repetir sua atividade exploratória. Muito menos conversam com ele sobre esta experiência, conforme podemos ler no excerto da primeira observação: "[...] o bebê pegou 0 brinquedo, era uma espécie de chocalho, levou-o à boca, tirou da boca, mexeu-o com a mão direita, repetiu este movimento, e o brinquedo caiu. Acompanhou com os olhos o brinquedo no chão, que outra criança pegou e começou a brincar. Surge no chão uma bola vermelha, o bebêa acompanha com os olhos. Um menino a empurra eengatinhaatrás dabola, o bebê continua a seguir a bola e 0 menino [...]."

Ao seguirmos a esteira do pensamento de Stern (1997), verificamos que ele, ao conceituar envelope protonarrativo, baseia-se na "noção de que a motivação dirigida para um objetivo é central para um entendimento do comportamento humano". Retornando às observações, fica o questionamento: qual seráamotivação que o bebêobservado encontra, quando não recebe de volta os brinquedos que caem de suas mãos? Verifica-se uma ausência de envelope protonarrativo nestas observações, eis que há a necessidade de uma verbalização que vincule a experiência ao afeto, e este, à narratividade. 


\section{Implicações para a formação do apego}

0 apego é construído com o passar do tempo: não se nasce apegado a alguém ou a alguma coisa. Nós, humanos, e alguns animais, temos a capacidade de desenvolver esse sentimento, que produz o desejo de estar sempre com aquela pessoa que nos é importante; que nos proporciona uma sensação de bem-estar e segurança; que irá nos acompanhar, diminuindo, assim, a ansiedade e 0 sofrimento que são inerentes à condição humana.

Sabemos que "a qualidade dos cuidados parentais que uma criança recebe em seus primeiros anos de vida é de importância vital para a sua saúde mental futura" (Bowlby, 1995), como, também, que o modo pelo qual esses cuidados são desempenhados "pelos pais, ou seus cuidadores, determina, em grau considerável, se a criança será mentalmente saudável ao crescer" (Bowlby, 1990).

O choa-Torres e Lelong (2004), em seu texto A função parental: Uma abordagem a partir da teoria do apego, contextualizando as contribuições da teoria do apego, afirmam que 0 apego é estabelecido no momento em que a mãe, ou aquela pessoa que desempenha o papel de cuidadora, satisfizer a necessidade de contato social do bebê, onde "o mais puro sinal de apego é a capacidade de enfrentar a separação, nos estágios apropriados do desenvolvimento da criança" (Brazelton, 1988).

Percebe-se, assim, que nem todos os apegos são saudáveis, ou produtores de bons vínculos. Quem nos possibilitou uma visão mais clara sobre as formas através das quais o apego está internalizado nas crianças, foi Mary Ainsworth. A través de "seus estudosno meio natural em Uganda e, posteriormente, em Baltimore" (Guédeney, 2002), forneceu dados para a categorização da vinculação e 0 "estilo de maternagem correspondente" (Guédeney, Guédeney, 2004), colocando de forma clara a importância da sensibilidade da mãe, ou do cuidador, para que se obtenha um apego seguro. Nessa modalidade de apego, de acordo com N. Fichtner (comunicação pessoal, 18 de dezembro de 2004) "encontramos pais que exercem suas funções parentais com amor, cuidado, respeitando os pontos críticos e as crises do desenvolvimento humano, da infância à vida adulta". Nolte (2003) refere que os pais são os primeiros depositários do crédito e da confiança dos filhos. Esses se sentirão seguros no momento em que tiverem a certeza de que aqueles estarão sempre disponíveis. A confiança é desenvolvida nas crianças de forma gradual, ao longo dos anos e das experiências.

Conforme o pensamento de Ainsworth, encontramos o segundo modelo de apego, que é 0 contrário do primeiro, ou seja, um apego inseguro, caracterizado pela resistência em se deixar envolver e a ansiedade quando desta possibilidade de envolvimento. Essa modalidade de apego caracteriza-se pela presença da incerteza e da insegurança na mente da criança, podendo também ser considerada como apego inseguro-evitante ou apego inseguro-ambivalente (resistente).

Por fim, de acordo com S. Célia (comunicação pessoal, 17 de abril de 2004) "temos também o apego desestruturantee/ ou desorganizante, em que as crianças dotadas deste sentimento não confiam em ninguém e transformam seu sentimento em doenças somáticas, relacionadas geralmente com as vias urinárias." Dessa forma, a qualidade da consciência dependerá das relações de apego nos primeiros anos de vida, pois essas são as primeiras relações que são internalizadas e estampadas na nossa consciência. "Estes modelos representativos das experiências relacionais infantis governam as futuras representações de si e dos outros" (Paulon, 1996), determinando assim a personalidade adulta.

Diante do exposto sobre o apego, resta 0 questionamento: qual será o laço que 0 bebê observado irá formar, ou já formou? Pois sabemos que é "o vínculo de apego que faz com que o bebê queira estar 'próximo da pessoa à qual ele pertence', que é a pessoa que cuida do bebê" (Mélega, 1997), o quenem sempreépossível, pois elepede, por diversas vezes, o colo das monitoras, e estas o negam. Vejase 0 seguinte excerto das observações: “... o bebê observado deixou a colher na mesa e olhava em direção da monitora, que agora voltava de novo da lavanderia, levantava seus braços como quem pede um colo, mas ela o viu e disse: 'agora tem que comer, não dá para dar colo'[...]”' (excerto da 3aobservação).

Está claro que o apego seguro possibilitará, num futuro próximo, o desapego, colaborando também com aformação deum fenômeno chamado de resiliência. "Com efeito, resiliência foi definida por Rutter e Garmezy como a capacidade de recuperar e manter um comportamento adaptado após um dano" (Célia, 2002). Na saúde mental, essa palavra é "empregada para enfatizar as condições nas quais uma criança poderesistir a um traumatismo ou a condições difíceis e manter a integridade de seu desenvolvimento psicológico" (Guédeney, 2002). 
Rodriguez (2005) crê que o conceito de resiliência evidencia uma combinação particular de fatores protetores, sendo difícil elencá-los, pois a existência do imponderável é determinante. V. Guerra (comunicação pessoal, 22 de julho de 2006) relacionou algumas "características que compõem um sujeito resiliente, tais como: permeabilidade de recursos, capacidade de espera, capacidade de brincar só, não-fixação na frustração, capacidade de dizer não, autorregulação e autoconfiança."

No bebê observado, percebemos alguns dosfatoresquecompõem aresiliência. D entreoutros, no excerto da terceira observação, lemos que, por seis vezes, ele solicita "colo" e não recebe o que demonstra sua permeabilidade: (1) "[...] do caminho ele se aproximava das pernas da monitora, como que pedindo um colinho [...]"; (2) "[...] o bebê observado deixou a colher na mesa e olhava em direção da monitora, que agora voltava da lavanderia, ele levantava seus braços como quem pede um colo, ela 0 viu e disse: 'agora tem que comer, não dá para dar colo' [...]"; (3) "[...] ele começou a chorar, também olhava para a monitora e erguia os bracinhos, ao que ela dizia: 'agora não dá, tenho quever o que estes dois fizeram' [...]"; (4) “[...] o bebêobservado ficou sentado, choramingando eerguendo seusbracinhos, amonitora nem o olhou, e como ele ficou porúltimo, a monitora o pegou edisse: 'ah, eu sei que tu quéum colinho, mas tá muito manhoso!' [...]"; (5) "[...] ofereceram água nas mamadeiras para cada bebê, uns aceitavam, outros não, o bebê observado não quis, foi para perto de um berço e ficou parado olhando a monitora. $Q$ uando esta o viu, ele estendeu os braços, ao que ela disse: 'mas agora vamo brincá um pouquinho, olha aqui umas bolas!' [...]" e (6) "[...] o bebê observado ficou apenas com uma expressão de desapontamento no rosto e voltou seu olhar para a monitora que estava próxima dele, ergueu seus braços em direção a ela, mas ela não o viu."

Aliada a sua permeabilidade, percebemos suacapacidade de dizernão, especificamentequando lhe é oferecido o lanche e ele fecha a boca cada vez que a monitora se aproxima com a colher cheia de alimento ("[...] o bebê observado fechava a boca cada vez que a monitora se aproximava com a colher [...]" (excerto da 3a observação)); e a negação, quando lhe é oferecida a mamadeira com água ("[...] as monitoras ofereceram água nas mamadeiras para cada bebê, uns aceitavam, outros não, o bebê observado não quis, foi para perto de um berço e ficou parado olhando [...]" (excerto da 3 a observação)); bem como a sua capacidade de brincar só, visualizada quando da segunda observação, no momento em que o bebê observado brinca com 0 brinquedo azul sobre a parede ("[...] parecia ser um carrinho de lego grande, com somente uma roda amarela. D aí se dirigiu até a parede que havia entre os berços da janela e os berços da parede e ficou andando e batendo com ele nesta parede, depois fez o mesmo movimento no berço, ia da parede para 0 berço e deste para aquela [...] continuando com 0 brinquedo na mão [...]” (excerto da 2ª observação)).

\section{CON SIDERAÇÕES FINAIS}

Inúmeros são os pais que, ao deixarem seus filhos em creches ou escolas infantis, buscam muito mais do que a aprendizagem para seus filhos; buscam que eles existam, sejam olhados, "encontrados, como Amparo o foi por Teodoro" (Brum, 2004). Oxalá possamos, através de nossas observações eatividades profissionais, conceder a bebês, como o bebê observado, não apenas cuidados materiais, mas também um amparo, uma atenção de forma integral, da mesma forma como Amparo recebeu de Teodoro (Wierzchowski, 1999). Para tanto, necessário é que o ambiente frequentado pelo bebê esteja apoiado em "fatores que favoreçam a credibilidade, a autossuficiência, que acredite na independentização, que não favoreça só a dependência, acreditando sempre que o lar e suas vivências estão embasadas nas vivências do cotidiano e que, como tal, vivemos bons e maus momentos" (Célia, 2002).

\section{REFERÊNCIAS}

Bowlby, J. (1990). Formação e rompimento dos laços afetivos. São Paulo: Martins Fontes.

Bowlby, J. (1995). Cuidados maternos e saúde mental. São Paulo: Martins Fontes.

Brazelton, B. T. (1988). 0 desenvolvimento do apego: Uma família em formação. Porto Alegre: Artes Médicas.

Brazelton, B. T., \& Cramer, B. G. (1992). As primeiras relações. São Paulo: Martins Fontes.

Brum, E. (2004). Patologias do vazio: Um desafio à prática clínica contemporânea. Revista: Psicologia Ciência e Profissão, 24, 48-53. 
Bujes, M. I. E. (2001). Escola infantil: Pra que te quero. In M. Craidy, G. E. P. da Kaercher, G. E. P. da S. E ducação infantil: Pra que te quero. (pp.13-22). Porto Alegre: Artmed.

Célia, S. (2002). A capacitação da resiliência e a formação da pele psicossocial (envelope). In L. Correia Filho, M. E. G. Corrêa, P. S. França. (O rg.). Novos olhares sobre a gestação e a criança até os três anos: Saúde perinatal, educação e desenvolvimento do bebê. (pp. 494-502). Brasília: L. G. E.

Ferreira, A. B. H. Novo Aurélio século XXI: 0 dicionário da língua portuguesa. Rio de Janeiro: Nova Fronteira, 1999.

Gaddini, R. (1982). Il processo maturativo: Studi sul pensiero di Winnicott. Padova: CLEUP.

Golse, B. (2003). Sobre a psicoterapia paibebê: Narratividade, filiação e transmissão. São Paulo: Casa do Psicólogo.

Guédeney, A. (2002). 0 apego e a resiliência: teoria, clínica e política social. In L. c. Filho, M. E. G. Corrêa, P. S. França. (O rg.). N ovos olhares sobre a gestação e a criança até os três anos: saúde perinatal, educação e desenvolvimento do bebê. (pp.503-511). Brasília: L. G. E.

G uédeney, A., G uédeney, N. (2004). Vinculação: Conceitos e aplicações. Portugal: Climepsi.

Mélega, M. P. (1997). A importância da construção do vínculo no desenvolvimento do indivíduo. In N. Fichtner. (O rg.). Prevenção, diagnóstico e tratamento dos transtornos mentais da infância e da adolescência: Um enfoque desenvolvimental. (pp. 2635). Porto Alegre: Artes Médicas.

Nolte, D. (2003). As crianças aprendem o que vivenciam. Rio de Janeiro: Sextante.

O choa-Torres, C., Lelong, I. (2004). A função parental: uma abordagem a partir da teoria do apego. In M. C. P. Silva. (O rg.). Ser pai, ser mãe parentalidade: Um desafio para o terceiro milênio. (pp. 123-131). São Paulo: Casa do Psicólogo.

Paulon, E. B. (1996). Uma psicanálise científica. Revista da Faculdade de Psicologia da PUC-SP, 3, 111-118.
Pessoa, F. (1998). Poemas de amor de Fernando Pessoa. Rio de Janeiro: Ediouro.

Rodríguez, D. H. (2005). O humor como indicador de resiliência. In A. Melillo, E. N. S. OJEDA. (O rg.). Resiliência: Descobrindo as próprias fortalezas. (pp. 131-138). Porto Alegre: Artmed.

Rizzo, Gilda. (1984). Creche: Organização, montagem e funcionamento. Rio de Janeiro: Livraria Francisco Alves.

Stern, D. N. (1997). A constelação da maternidade. Porto Alegre: Artes Médicas.

Stern, D. N. (2007). 0 momento presente na psicoterapia e na vida cotidiana. Rio de Janeiro: Record.

Wierzchowski, L. (1999). A prata do tempo. Porto Alegre: LPM.

Winnicott, D. W. (1983). 0 ambiente e os processos de maturação: Estudos sobre a teoria do desenvolvimento emocional. Porto Alegre: Artmed.

Winnicott, D. W. (2000). Da pediatria à psicanálise: Obras escolhidas. Rio de Janeiro: Imago.

Recebido: 11/ 11/ 2007

Recived 11/11/2007

Aprovado: 04/ 06/ 2008

Approved 06/ 04/2008 